New window on Tibetan tectonics The latest reports from the Sino-French expedition in Tibet show a rich and surprising harvest of discovery. Has not the time come for more open access to this important region?

TIBET has always been a mysterious place. In the nineteenth century, wide-eyed explorers wrote of the region with an innocence unclouded by the circumstance that Marco Polo had passed that way some centuries earlier. Physical isolation has all along been enhanced by human geography, and in particular by the self-imposed isolation of the Tibetan people, broken chiefly by expeditions bent on climbing Mount Everest.The consequence is that very little has been learned at first hand of the most rudimentary geological characteristics of this remarkable region and that many of the attempts in the past few years to relate the tectonic structure Tibet (and much of the rest of central Asia) to the tectonic collision of the Indian subcontinent with the Asian land-mass have had to rely to an unhealthy degree on inferences from topographical features.

Now, at last, there is a good chance that some of these uncertainties will be removed. The group of articles appearing on pages $17-36$ is the second instalment of the fruits of the Sino-French collaboration on the geology of Tibet (see also Nature 294, 405-417; 1981). In two successive seasons (1980 and 1981), modern techniques have for the first time been applied to the study of the gross tectonic structure of Tibet. By means of seismic records from artificial explosions, it has in particular been possible to map beneath Tibet the Mohorovicic discontinuity which is probably the best indicator of the continental basement. The result is both important and surprising.

That the collision of the Indian subcontinent with the Asian underbelly must have had a dominating influence on the structure of central Asia has been evident since it was first recognized that the Indian subcontinent traversed the whole length of the Indian Ocean from about 50 million years ago until its collision with Asia rather more than 20 million years ago. The join between the two continents is recognizable in the long east-west suture along part of which the Brahmaputra flows eastwards, north of the Himalayas. The Himalayas themselves are explicable as tectonic consequences of the collision between two land-masses - formed from material uplifted from the northern leading edge of the Indian subcontinent and partly metamorphosed in the process.

In recent years, the bigger puzzle has been that of understanding what may have happened north of the suture, beneath
Tibet itself. The great elevation of central Asia suggests that an ancient continental crust has been thickened, while the predominantly east-west alignment of major features between the Caspian Sea in the west and mainland China in the east suggests crustal shortening in a northSouth direction and extension at right angles. Whether the elevation of central Asia might be explained by the addition of Indian material to the underlying basement, almost as if the southern continent were sliding beneath Asia, has been a lively issue amongst geophysicists.

What now emerges from the Sino-French study of Tibet along two north-south traverses is that the simple picture of a once-and-for-all collision is too simple. The most striking result of the data gathered by the 1981 expedition is that there is a second suture in the tectonic structure of Tibet which, on the face of things, is in every way comparable with the southern suture but some hundreds of kilometres further north. The inference is that the collision of India with the underside of Asia was preceded some tens of millions of years earlier by the collision of another continental fragment with the same region. And that layer of material has been thickened, and elongated from the east to west, between the anvil of the main body of Asia to the north and the stillmoving hammer of India, now shown to be moving relative to the Tibetan blocks at about 5 centimetres a year.

The evidence for this new view of the recent history of south-central Asia is impressive. Palaeomagnetic measurements show that the Lhasa block, the first tectonic structure north of the Himalayas, was sited at or south of the Equator in Cretaceous times. In the region covered by the Sino-French surveys, the continental basement is a patchwork suggesting that the high plateau of central Asia is made up not simply of two fragments (the Indian subcontinent and its predecessor) but of several. And there is evidence to suggest just how relics of past continental fragments underline each other, contributing to the thickening of the continental crust throughout this region.

For those with an interest in the evolution of Gondwanaland, these developments must be portentous. On the simplest reconstructions, Gondwanaland is an amalgam of those continents lying on or south of the Equator. Both the manner of their assembly into a larger continent and the timing of their dispersal are reasonably well catalogued. But the reconstruction of the supposedly earlier super-continent in which the northern land-masses are also combined has always been more speculative and less certain.

If now it is clear that the shapes of many of these structures have been distorted by later tectonic events, the awkwardness of more ambitious reconstructions will be better understood. But naturally, the question will be sharpened why a whole series of continental fragments should have been sent scurrying north across the Indian Ocean in the past few hundred million years. Why in that direction and not some other? Or was the assembly of southern Asia an even more complicated process than it now appears to have been?

For others, the work now published is still not enough to satisfy legitimate curiosity about this geologically important region. Moreover, it is clear that what has been accomplished in a few short seasons of work with modern equipment is merely a scratching of the surface. In an ideal world, there would now follow a systematic programme of exploration designed to amass the details on which accurate interpretations can alone be based. (Why, in any case, should there have been a single land mass in the early Cambrian?)

The obvious snag is that Tibet is almost as inaccessible now as in the days before its annexation by the People's Republic of China. The collaboration with the French is the only significant opening to the outside world so far. In everybody's interests, those of the people of China especially, there need to be many more. And readers of the articles now published will be struck by the irony that the 1981 Sino-French expedition was prevented for administrative reasons from continuing north beyond Tibet into China proper. The time has surely come when such restrictions should be swept away.

John Maddox

\section{Sir Charles Frank}

IN an article on snowflakes in Nature on 3 November (306, 13; 1983), it was erroneously stated that Professor F.C. Frank (whose name was mis-spelled) of the University of Bristol had died in 1982. Nature is glad to report that this is not the case and wishes to apologize to Sir Charles, his friends and colleagues and its other readers for this embarrassing mistake. 